\title{
Comparison of 3 Different Methods in The Antibiotic Prophylaxis for Prostate Biopsy
}

\section{Prostat Biyopsisi Antibiyotik Proflaksisinde 3 Farklı Yöntemin Karşılaştırılması}

\author{
Gökhan Sönmez ${ }^{1}$, Murat Keske ${ }^{1}$, Fatih Demir ${ }^{1}$, Nurullah Hamidi ${ }^{2}$, Mert Ali Karadag ${ }^{1}$ \\ ${ }^{1}$ Kayseri Şehir Hastanesi, Üroloji Kliniği, Kayseri \\ ${ }^{2}$ Atatürk Eğitim Ve Araştırma Hastanesi, Üroloji Kliniği, Ankara
}

Dergiye Ulaşma Tarihi: 14.05.2019 Dergiye Kabul Tarihi: 17.06.2019 Doi: 10.5505/aot.2020.70446

\section{ÖZET}

Amaç: Prostat Kanseri (PCa) kesin tanısında altın standart yöntem prostat iğne (PB) biyopsisidir. PB sonrası üriner sistem enfeksiyonları gibi hayatı tehdit eden önemli komplikasyonlar meydana gelebilir. Bu nedenle PB için uygulanacak antibiyotik proflaksisi yöntemi önem taşımaktadır. Bu çalışmada siprofloksasin, gentamisin ve siprofloksasin + gentamisin kombinasyonlarının PB proflaksisindeki etkinliklerinin karşılaştırılması amaçlanmıştır.

Yöntem: Bu retrospektif çalışmada, prostat kanseri şüphesi nedeniyle transrektal ultrasonografi kılavuzluğunda standart 1012 kor prostat biyopsisi uygulanan hastaların verileri analiz edilmiştir. Hastalar uygulanan proflaksi yöntemine göre 3 gruba ayrılmıştır; 1) işlemden önce tek doz im. gentamisin $80 \mathrm{mg}$ uygulananlar, 2) işlemden 24 saat önce başlanarak günde $2 \mathrm{kez}$ toplam 3 gün (oral) siprofloksasin $500 \mathrm{mg}$ uygulananlar, 3) her ikisinin kombinasyonu uygulanalar. Grupların ateşli üriner sistem enfeksiyon (AÜSE) oranlarının yanı sıra yaş, serum prostat spesifik antijen (PSA) düzeyleri gibi bazı demografik ve klinik verileri kaydedilerek karşılaştırılmıştır.

Bulgular: Çalışmaya toplam 180 hasta dâhil edildi (Grup 1=67, Grup 2=51, Grup 3=62). Tüm hastaların yaş ortalaması $64.41( \pm 7.08)$ yıl, ortanca PSA değerleri ise $8.90(6.40-16.70) \mathrm{ng} / \mathrm{ml}$ idi. Hastalarda biyopsi sonrası AÜSE görülme oranı \%4.4 idi. Grupların ortalama yaş, vücut kitle indeksi, ortanca prostat hacimleri, ortanca PSA düzeyleri ve kanser saptanma oranları istatistiksel olarak benzerdi. En fazla AÜSE Grup 2'de tespit edilirken (\%11.7), Grup 1 ve Grup 3 ise AÜSE oranları açısından benzerdi (sırasıyla \%1.4, \%1.6). En sık izole edilen etken Escherichia coli idi.

Sonuç: Çalışmamızın sonuçlarına göre, biyopsi öncesi tek doz im. gentamisin uygulanarak yapılan proflaksi, tek başına oral siprofloksasin ile yapılan antibiyotik proflaksisine göre daha etkin görünmektedir. Tek doz gentamisin ile kombinasyon proflaksisi etkinlikleri benzer bulunmakla birlikte, uygulama kolaylığı ve akılcı antibiyotik kullanımı açısından işlem öncesi tek doz gentamisin ile proflaksi önermekteyiz.

Anahtar Kelimeler: Biyopsi, Enfeksiyon, Proflaksi, Prostat

\begin{abstract}
Introduction: The gold standard method for the definitive diagnosis of Prostate Cancer (PCa) is prostate needle biopsy (PB). Significant life-threatening complications such as urinary tract infections may occur after PB. Therefore, the antibiotic prophylaxis method for $\mathrm{PB}$ is important. The aim of this study was to compare the efficacy of ciprofloxacin, gentamicin and ciprofloxacin + gentamicin in PB prophylaxis.

Methods: In this retrospective study, the data of patients who underwent standard 10-12 core prostate biopsy under the guidance of transrectal ultrasonography because of the suspicion of prostate cancer were analyzed. Patients were divided into 3 groups according to the applied prophylaxis method; 1) Single dose im. gentamicin $160 \mathrm{mg}$ administered before biopsy. 2) Ciprofloxacin $500 \mathrm{mg}$ administered twice a day for a total of 3 days (oral) starting 24 hours before biopsy. 3) The combination of both drugs applied. Febrile urinary tract infection (FUTI) rates of the groups, as well as some demographic and clinical data such as age, serum prostate specific antigen (PSA) levels, were recorded and compared.

Results: A total of 180 patients were included in the study (Group 1=67, Group $2=51$, Group $3=62$ patients). The mean age of all patients was $64.41( \pm 7.08)$ years, and the median PSA values were $8.90(6.40-16.70) \mathrm{ng} / \mathrm{ml}$. The incidence of FUTI after biopsy was $4.4 \%$. The mean age, mean body mass index, median prostate volumes, median PSA levels and cancer detection rates of the groups were statistically similar. While the most number of
\end{abstract}


FUTIs were detected in Group 2 (11.7\%), Group 1 and Group 3 were similar in terms of FUTI rates $(1.4 \%, 1.6 \%$, respectively). The most commonly isolated agent was Escherichia coli.

Conclusions: According to the results of our study, a single dose im. prophylaxis with gentamicin appears to be a more effective prophylaxis method than antibiotic prophylaxis with oral ciprofloxacin alone. Although the effectiveness of single-dose gentamicin and combination prophylaxis are similar, because of the ease of administration and the choice of rational antibiotics, we recommend single-dose gentamicin.

Key Words: Biopsy, Infection, Prostate, Prophylaxis

\section{GİRIŞ}

Prostat kanseri (PCa) dünyada erkeklerde en sik görülen ikinci kanser türüdür (1). PCa tanısı temel olarak şüpheli parmakla rektal muayene (PRM) ve/veya yüksek serum prostat spesifik antijen (PSA) düzeyleri sonrası yapılan transrektal ultrasonografi kilavuzluğunda prostat biyopsisi (TRUS-B) ile konulur (2).

Prostat biyopsisi (PB) sonrası hematüri, pelvik ağrı, hematokezya gibi bazı sık komplikasyonların yanında asemptomatik bakteriüri, akut bakteriel prostatit, pyelonefrit, sepsis ve septik şok gibi üriner sistem kaynaklı enfeksiyonlar da meydana gelebilir. Bu nedenle tüm hastalara biyopsi işlemi öncesi etkili bir antibiyotik proflaksisi son derece önem taşımaktadır (3).

Siprofloksasin,

seftriakson, fosfomisin, gentamisin, levofloksasin prostat biyopsisinde etkinliği gösterilmiş bazı antibiyotiklerdir (4-6). Ancak proflakside hangi antimikrobiyal ajanın tercih edilmesi gerektiği konusu ise tartışmalı olup direnç faktörü antibiyotik seçimine yön vermektedir (7).

$\mathrm{Bu}$ retrospektif çalışmada, kliniğimizde rutin olarak uygulanmakta olan 3 farklı PB antibiyotik proflaksisi yönteminin (gentamisin, siprofloksasin, gentamisin + siprofloksasin) etkinliklerinin karşılaştırılması amaçlanmıştır.

\section{GEREÇ ve YÖNTEM}

Hasta seçimi ve çalışma dizaynı: Bu çalışmaya Haziran 2018-Nisan 2019 tarihleri arasinda Kayseri Şehir Hastanesi Üroloji Kliniğinde PCa şüphesi nedeniyle 10-12 kor standart TRUS-B işlemi uygulanan hastalar dahil edilmiştir. Hastalar, işlemden önce tek doz (intramusküler [im.]) gentamisin $160 \mathrm{mg}$ uygulanan hastalar (Grup 1), işlemden 24 saat önce başlanarak günde $2 \mathrm{kez}$ toplam 3 gün (oral [o.]) siprofloksasin $500 \mathrm{mg}$ uygulananlar (Grup 2) ve her ikisinin kombinasyonu uygulanan hastalar (Grup 3) olmak üzere 3 gruba ayrılmıştır. Bu yöntemler dişında proflaksi uygulanan hastalar, işlem sonrası takipleri veya klinik verileri eksik olan hastalar, işlemden önce 1 hafta içinde bilinen antibiyotik kullanımı olanlar çalışmada dışlama kriterleri olarak belirlenmiştir. Hastada üriner sistem dışında bir enfeksiyon odağ yokken idrar kültüründe üreme olması ve/veya idrar mikroskopisinde yüksek lökosit varlığ ile bunlara eşlik eden yüksek ateş $\left(>38.0 \mathrm{C}^{0}\right)$, biyopsiye bağlı ateşli üriner sistem enfeksiyonu (AÜSE) olarak kabul edilmiştir. Grupların AÜSE oranlarının dışında yaş, vücut kitle indeksi (VKİ), serum PSA değerleri, toplam prostat hacimleri ve kanser tespit edilme oranları gibi bazı demografik ve klinik verileri analiz edilmiştir.

\section{Biyopsi Hazırlı̆̆ı ve Biyopsi İşlemlerinin} Uygulanmast: PB öncesi tüm hastalarda temiz idrar kültürü görülmüştür. Herhangi bir nedenle antikoagülan-antiagregan gibi kanama bozukluğu yapacak ilaç kullanan hastalar ilgili bölümlerle konsülte edilerek, bu ilaçlar özelliklerine göre belirlenen süre ile kesilmiştir. Barsak hazırlığı veya işlem sırasında rektal temizlik uygulanmamıştır. Biyopsi işlemleri poliklinik şartlarında lokal anestezi ile uygulanmıştır. Lokal anestezik olarak 0.2 gr lidokain içeren kayganlaştırıcı jel ve her iki periprostatik demete $\% 2$ prilokain enjeksiyonu (5 cc serum fizyolojik ile sulandırılarak) kullanılmıştır. Biyopsi işlemleri, ultrasonografi cihazı (Toshiba Nemio XG, Japonya) ve transrektal prop (Toshiba, PVF-620ST) yardımıla lateral dekübit pozisyonunda uygulanmıştır. Biyopsiler 10-12 kor standart prostat biyopsisi şeklinde uygulanmıştır.

İstatistiksel Analiz: İstatistiksel analizler SPSS 22.0 (IBM corp. USA) programı kullanilarak gerçekleştirilmiştir. Dağılım özelliklerinin belirlenmesi için Shapiro-Wilk's testi ve Histogram grafikleri kullanılmıştır. Veriler dağılım özelliklerine göre ortalama $( \pm$ standart sapma) veya ortanca (Interquartel Range [IQR]) 
olarak ifade edilmiştir. Normal dağılım gösteren çoklu gruplara ait sayısal verilerin analizi için tek yönlü varyans analizleri ile gerçekleştirilmiştir. $\mathrm{Bu}$ testte Post Hoc test olarak Tukey testi kullanılmıştır. Normal dağılım göstermeyen sayısal verilerin analizi için Mann Whitney-U testi kullanılmıştır. Kategorik veriler ise Ki-kare ve Fisher's-Exact testleri ile karşılaştırılmıştır. P değerinin 0.05 'ten küçük olması istatistiksel olarak anlamlı kabul edilmiştir.

\section{BULGULAR}

Çalışmaya toplam 183 hasta dâhil edildi. Tüm hastaların yaş ortalaması $64.41( \pm 7.08)$ yıl, ortanca PSA değerleri ise 8.90 (6.40-16.70) $\mathrm{ng} / \mathrm{ml}$ idi. Çalışmaya dâhil edilen tüm hastalara ait bazı demografik ve klinik veriler Tablo-1'de özetlenmiştir. 67 hastaya işlem öncesi tek doz gentamisin $160 \mathrm{mg} \mathrm{im}$. (Grup 1), 51 hastaya işlemden 24 saat önce başlanarak 12 saat ara ile 3 gün Siprofloksasin $500 \mathrm{mg} o$. (Grup 2), 67 hastaya ise her iki yöntemin kombinasyonu (Grup 3) uygulanmıştı. Gruplar kendi aralarında karşılaştırıldığında yaş, VKİ, serum PSA düzeyleri, prostat hacimleri ve kanser saptanma oranları bakımından gruplar arası fark yoktu. AÜSE oranları ise Grup 1 ve Grup 3 için benzer iken $(p=0.956)$, Yalnızca oral siprofloksasin ile proflaksi uygulanan hastalarda daha fazla oranda AÜSE geliştiği görüldü (bknz. Tablo 2). AÜSE gelişen hastaların verileri ayrıca değerlendirildiğinde bu hastaların tamamının idrar kültüründe Escherichia coli üremesi olduğu saptand1. AÜSE görülen hastaların bazı demografik ve klinik özellikleri Tablo 3 'te verilmiştir.

Tablo 1: Çalışmaya dâhil edilen tüm hastaların demografik ve klinik özellikleri

\begin{tabular}{|l|l|}
\hline \multicolumn{1}{|c|}{ Parametre } & \multicolumn{1}{c|}{ Dĕger (n=180) } \\
\hline Yaş (Y1l) & $64.41 \pm 7.08$ \\
\hline Vucüt Kitle İndeksi $\left(\mathrm{kg} / \mathrm{m}^{2}\right)$ & $24.90 \pm 2.89$ \\
\hline PSA (ng/dl) & $8.90(6.40-16.70)$ \\
\hline Prostat Hacmi $\left(\mathrm{mm}^{3}\right)$ & $58.00(49.00-71.00)$ \\
\hline Kanser Tespit Edilme Oranı (n, \%) & $76 / 180(\% 42.2)$ \\
\hline Ateşli Üriner Enfeksiyon Oranı (n, \%) & $8 / 180(\% 4.4)$ \\
\hline
\end{tabular}

Tablo-2: Antibiyotik proflaksisine göre gruplara ayrılan hastaların demografik ve klinik özelliklerinin karşılaştırılması.

\begin{tabular}{|c|c|c|c|c|}
\hline Parametre & Grup-1 (n=67) & Grup-2 (n=51) & Grup-3 (n=62) & $\mathbf{p}$ \\
\hline Yaş $\left(Y_{11}\right)^{\mathrm{x}}$ & $67.69(+7.33)$ & $66.28(+7.65)$ & $65.15(+6.08)$ & 0.124 \\
\hline Vucüt Kitle İndeksi $\left(\mathrm{kg} / \mathrm{m}^{2}\right)^{x}$ & $25.12( \pm 3.09)$ & $24.33( \pm 2.86)$ & $25.17( \pm 2.65)$ & 0.226 \\
\hline Prostat Hacmi $\left(\mathrm{mm}^{3}\right)^{\mathrm{y}}$ & $58.00(\overline{47.00-71.00)}$ & $57.00(48.75-71.25)$ & $\begin{array}{l}60.00 \quad(49.75- \\
73.00)\end{array}$ & 0.827 \\
\hline PSA $(\mathrm{ng} / \mathrm{dl})^{\mathrm{y}}$ & $11.10(7.30-23.10)$ & $8.45(5.95-16.85)$ & $9.30(6.65-15.25)$ & 0.106 \\
\hline $\begin{array}{l}\text { Kanser Tespit Edilme Oran1 } \\
(\mathrm{n}, \%)^{\mathrm{z}}\end{array}$ & $26 / 67(\% 38.8)$ & $21 / 51(\% 41.1)$ & $29 / 62(\% 46.7)$ & 0.588 \\
\hline $\begin{array}{l}\text { Ateşli Üriner } \text { Enfeksiyon } \\
\text { Oranı }(\mathrm{n}, \%)^{\mathrm{z}}\end{array}$ & $1 / 67(\% 1.4)^{\mathrm{a}}$ & $6 / 51(\% 11.7)^{\mathrm{b}}$ & $1 / 62(\% 1.6)^{\mathrm{c}}$ & $\begin{array}{l}\mathrm{P}^{\mathrm{a}-\mathrm{b}}: 0.049 \\
\mathrm{P}^{\mathrm{a}-\mathrm{c}}: 0.956 \\
\mathrm{P}^{\mathrm{b}-\mathrm{c}}: 0.044\end{array}$ \\
\hline
\end{tabular}

PSA: Prostat spesifik antijen, x: One-Way Anova y: Mann Whitney-U z: Ki-Kare veya Fisher Exact

Tablo-3: Prostat biyopsisi sonrası ateşli üriner sistem enfeksiyonu gelişen sekiz hastanın demografik ve klinik verileri.

\begin{tabular}{|l|l|l|l|l|l|l|l|l|}
\hline Grup & $\begin{array}{l}\text { Yaş } \\
(\mathbf{y l})\end{array}$ & $\begin{array}{l}\text { VKİ } \\
\left(\mathbf{k g} / \mathbf{m}^{\mathbf{2}}\right)\end{array}$ & $\begin{array}{l}\text { PSA } \\
(\mathbf{n g} / \mathbf{m l})\end{array}$ & $\begin{array}{l}\text { Beyaz } \\
\text { Küre }\end{array}$ & CRP & $\begin{array}{l}\text { Kültür } \\
\text { Sonucu }\end{array}$ & $\begin{array}{l}\text { Histo- } \\
\text { patoloji }\end{array}$ & $\begin{array}{l}\text { Direnç } \\
\text { Durumu }\end{array}$ \\
\hline 1 & 72 & 25.1 & 17.1 & 17.150 & 86 & E.coli & Gleason 3+4 & SD, GD \\
\hline 2 & 71 & 31.2 & 11.6 & 16.200 & 20 & E.coli & Benign & SD \\
\hline 2 & 55 & 26.4 & 3.6 & 12.850 & 45 & E.coli & Benign & SD \\
\hline 2 & 69 & 25.9 & 11.4 & 11.400 & 121 & E.coli & Benign & SD \\
\hline 2 & 58 & 28.7 & 5.0 & 10.660 & 48 & E.coli & Benign & SD \\
\hline 2 & 69 & 26.1 & 7.8 & 17.220 & 64 & E.coli & Gleason 3+3 & SD \\
\hline
\end{tabular}

Adress for correspondence: Doç. Dr. Mert Ali Karadağ, Şeker Mah. Kayseri Şehir Hastanesi. Genel Hastane Üroloji Polikliniği 1. Kocasinan Kayseri 38080 Kayseri - Türkiye 


\begin{tabular}{|l|l|l|l|l|l|l|l|l|}
\hline 2 & 55 & 20.8 & 6.3 & 21.200 & 6 & E.coli & Benign & SD \\
\hline 3 & 72 & 21.9 & 9.2 & 16.700 & 91 & E.coli & Gleason 3+3 & SD \\
\hline
\end{tabular}

SD: Siprofloksasin dirençli, GD: Gentamisin dirençli, PSA: Prostat spesifik antijen, CRP: C-Reaktif protein

\section{TARTIŞMA}

Çalışmamızın sonuçlarına göre en yüksek AÜSE oran1 grup 2'de görülürken (\%11.7) grup 1 ve grup 3 'te benzer oranlarda AÜSE tespit edilmiştir (sırasıyla, \%1.4 ve \%1.6). Sadece tek doz gentamisin ile siprofloksasin + gentamisin kombinasyonunda benzer sonuçlar elde edilse bile akılcı antibiyotik kullanımı açısından bu veriler çalışmamızda en uygun PB proflaksisi yönteminin işlem öncesi tek doz gentamisin 160 mg (im.) olduğunu göstermektedir. Literatürde siprofloksasin ve gentamisinin karşılaştırıldı tek çalışma 1991 yilında Roach ve ark. tarafından yayınlanmıştır (8). 55 hasta ile yapılan araştırmada 28 hastadan oluşan bir gruba işlemden önce ve sonra $500 \mathrm{mg}$ oral siprofloksasin verilirken, 27 hastadan oluşan diğer gruba işlemden önce ve sonra $1.5 \mathrm{mg} / \mathrm{kg}$ intravenöz gentamisin uygulanmıştır. Araştırmanın sonuçlarına göre siprofloksasin grubunda daha az oranda bakteriyemi ve bakteriüri görüldüğü raporlanmıştır ve yazarlar PB proflaksisinde siprofloksasinin daha etkin bir antibiyotik olduğunu savunmuşlardır. Çalışmanın sonuçlarının bizim sonuçlarımızla uyumsuz olmasının, söz konusu araştırmanın uzun süre önce yapılmış olmasından ve zamanla gelişen antibiyotik direnci faktöründen kaynaklanabileceği kanısındayız. 2009 yılında yapılan başka bir çalışmada ise biyopsiden 1 gün önce $500 \mathrm{mg} o$. siprofloksasin başlanan ve 3 gün devam edilen hastalar ile (siprofloksasin grubu), ek olarak işlemden hemen önce tek doz $80 \mathrm{mg} \mathrm{im}$. gentamisin uygulanan hastalar (siprofloksasin + gentamisin grubu) enfeksiyon oranları açısından karşılaştırılmışıtır (9). Toplam 741 hastanın dahil edildiği bu çalışmada siprofloksasin grubunda \%3.3 iken kombinasyon uygulanan grupta bu oran \%1.3 olarak tespit edilmiştir $(p=0.04)$ ve yazarlar PB öncesi kombinasyon proflaksisini önermişlerdir. $\mathrm{Bu}$ çalışmada bizim araştırmamızdan farklı olarak tek başına gentamisinin etkinliği değerlendirilmemiştir. Siprofloksasin + gentamisin uyguladığımız grupta sonuçlarımız bu araştırma ile benzer olmakla birlikte sadece siprofloksasin uyguladığımı grupta enfeksiyon oranlarımız bu çalışmaya göre oldukça yüksek bulunmuştur (\%11.7 - \%3.3). Bu durum çalışmamıza dâhil edilen hasta sayısının az olmasından ve bölgesel siprofloksasin direnç farklılıklarından kaynaklanıyor olabilir. Öyle ki, bölgemizde yapılan güncel bir çalışmaya göre siprofloksasin direcinin son y1llarda giderek arttığ1 ve $\% 32$ düzeylerine yükseldiği bildirilmiştir (10).

Tüm hastalar değerlendirildiğinde çalışmamızda AÜSE oranı \%4.4 olarak tespit edilmiştir. Sistematik bir derlemeye göre PB sonras1 \%2-6 oranlarında üriner sistem enfeksiyonları bildirilmektedir ve sonuçlarımız literatürle uyumlu bulunmuştur (3).

Çalışmamızda toplam 8 hastada AÜSE geliştiği görülmüştür. Bunların 6's1 siprofloksasin grubunda iken birer tanesi gentamisin ve siprofloksasin + gentamisin gruplarında idi. Hastaların tamamının idrar kültüründen izole edilen bakteri Escherichia coli idi. 2018 y1lında 3,550 hastanın geriye dönük verilerinin değerlendirildiği bir çalışmada PB sonrası üriner sistem enfeksiyonu gelişen hastaların \%97'sinde Escherichia coli izole edildiği bildirilmiştir (11). Literatürde benzer sonuçların elde edildiği başka çalışmalarda vardır (12). Çalışmamızda AÜSE gelişen 8 hastanın 7'sinde siprofloksasin direnci tespit edilirken, sadece gentamisin ile proflaksi uygulanan 1 hastanın antibiyogramında hem siprofloksasin hem gentamisin direnci tespit edilmiştir. Diğer bir deyişle, siprofloksasin dirençli Escherichia coli üreyen hastaların yalnızca \%12.5'inde gentamisin direnci mevcut bulunmuştur. 2008 y1linda PB uygulanan 1,273 hastanın sonuçlarının yayınlandığı bir çalışmada florokinolon direnci olan hastaların yalnızca $\% 22$ 'sinde gentamisin direnci olduğu raporlanmıştır (13).

PB için antibiyotik proflaksisinin tek doz mu yoksa 3 günlük çoklu dozlarda mı uygulanması gerektiği konusunda net fikir birliği yoktur. Tek doz proflaksinin yeterli olduğunu savunan araştırmacılar olduğu gibi tek doz proflaksinin yeterli olmayacağını raporlayan araştırmalarda 300 mevcuttur $(14,15)$. Çalışmamızda hastalara siprofloksasin oral yoldan ve işlemden 24 saat önce başlanarak 3 gün süre ile uygulanmıştır. 
PB sonras1 hayat1 tehdit eden enfeksiyon ve sepsis oranları genellikle \%1'in altında bildirilmektedir (3). 827 hasta ile yapilan bir çalışmada ürosepsis oranı $\% 0.2$ olarak raporlanmıştır. Bizim sonuçlarımıza göre ise hiçbir hastada ürosepsis gelişmemiştir. $\mathrm{Bu}$ durum çalışmaya dâhil edilen hasta sayısının söz konusu çalışmalara göre düşük olması ile açıklanabilir.

Çalışmamızın en önemli kısıtlayıcı yönleri hasta sayısının az olması ve retrospektif bir çalışma olması şeklinde sıralanabilir. Retrospektif özelliği nedeniyle yalnızca semptomatik hale gelen AÜSE oranlarının belirlenebilmiş olması, klinik olarak semptom vermemiş olabilecek bakteriüri, basit sistit gibi

\section{REFERANSLAR}

1. Torre LA, Bray F, Siegel RL, et al. Global cancer statistics, 2012. CA Cancer J Clin. 2015;65: 87-108.

2. Loeb S, Vellekoop A, Ahmed HU, et al. Systematic review of complications of prostate biopsy. Eur Urol. 2013;64: 876-92.

3. Wagenlehner FME, van Oostrum E, Tenke P, et al. Infective complications after prostate biopsy: outcome of the Global Prevalence Study of Infections in Urology (GPIU) 2010 and 2011, a prospective multinational multicentre prostate biopsy study. Eur Urol. 2013;63: 521-7.

4. Williamson DA, Roberts SA, Paterson DL, et al. Escherichia coli bloodstream infection after transrectal ultrasound-guided prostate biopsy: implications of fluoroquinolone-resistant sequence type 131 as a major causative pathogen. Clin Infect Dis. 2012;54: 1406-12. 335

5. European Association of Urology. Urological Infections. Prostate Biopy. European Association of Urology web site. http://uroweb.org/guideline/ urological-infections/\#note_360. Accessed April 25, 2018.

6. Fahmy AM, Kotb A, Youssif TA, Abdeldiam H. Fosfomycin antimicrobial prophylaxis for transrectal ultrasound-guided biopsy of the prostate: a prospective randomised study. Arab J Urol. 2016;14: 228-33.

7. Cuevas O, Oteo J, Lázaro E, et al. Significant ecological impact on the progression of fluoroquinolone resistance in Escherichia coli with increased community use of moxifloxacin, levofloxacin and amoxicillin/ clavulanic acid. J Antimicrob Chemother. 2011;66: 664-9.

8. Roach MB, Figueroa TE, McBride D, George WJ, Neal DE Jr. Ciprofloxacin versus gentamicin in enfeksiyöz tabloların değerlendirilememiş olması çalışmamızın diğer bir eksik 310 yönüdür. Ayrıca prostat biyopsisinin sik görülen komplikasyonlarından olan hematüri, pelvik ağrı, hematokezya gibi komplikasyonlar da değerlendirilememiştir.

Sonuç olarak, biyopsi öncesi tek doz im. gentamisin uygulanarak yapilan proflaksi, tek başına oral siprofloksasin ile yapılan yada kombinasyon şeklinde yapılan antibiyotik proflaksisine göre daha etkin ve uygulanabilir bir proflaksi yöntemi gibi görünmektedir. Konu ile ilgili daha fazla hasta say1lı, prospektif, çalıșmalara ihtiyaç vardır.

\section{Çıkar Çatışması: Yok}

prophylaxis against bacteremia in transrectal prostate needle biopsy. Urology. 1991;38: 84-7.

9. Ho HS, Ng LG, Tan YH, Yeo M, Cheng CW. Intramuscular Gentamicin Improves the Efficacy of Ciprofloxacin as an Antibiotic Prophylaxis for Transrectal Prostate Biopsy. Ann Acad Med Singapore. 2009;38: 212-6.

10. Bozcal E, Eldem V, Aydemir S, Skurnik M. The relationship between phylogenetic classification, virulence and antibiotic resistance of extraintestinal pathogenic Escherichia coli in İzmir province, Turkey. PeerJ. 2018; 24: 6:e5470.

11. Turk H, Un S, Sener GA, Yoldas M, Akdeniz F, Arslan E. Prostate Biopsy to Diagnose Acute Bacterial Prostatitis: Current Microbiological Spectrum, Sensitivity to Antibiotics, and Clinical Findings in Turkey. EJMO 2018;2: 91-6.

12. Hwang EC, Yu HS, Jung $S$, et al. Infectious Complications after Prostate Biopsy: A Prospective Multicenter Prostate Biopsy Study. Urogenit Tract Infect. 2016;11: 17-24

13. Feliciano J, Teper E, Ferrandino $M$, et al. The incidence of fluoroquinolone resistant infections after prostate biopsy--are fluoroquinolones still effective prophylaxis? J Urol. 2008;179: 952-5.

14. Zani EL, Clark OA, Rodrigues Netto N Jr. Antibiotic prophylaxis for transrectal prostate biopsy. Cochrane Database Syst Rev 2011;5: CD006576.

15. Briffaux $R$, Coloby $P$, Bruyere $B$, et al. One preoperative dose randomized against 3-day antibiotic prophylaxis for transrectal ultrasonography-guided prostate biopsy. BJU Int. 2009;103: 1069-73. 